\title{
IMPLEMENTAÇÃO DO CONCEITO DE MODELAGEM DA INFORMAÇÃO EM EMPRESAS PROJETISTAS: ANÁLISE DO PROCESSO DE GESTÃO DE PESSOAS
}

\author{
Katherine Fischer(1), Flavia Rodrigues de $\operatorname{Souza}^{(1)}$ \\ (1) Escola Politécnica da Universidade de São Paulo, São Paulo
}

\begin{abstract}
Resumo
As organizações a nível mundial estão renovando e adotando modelos de gestão de pessoas tendo o talento humano como determinante no sucesso do negócio, o que está acontecendo também no setor da construção civil designadamente em empresas projetistas. Atualmente, a busca pela utilização da Modelagem da Informação da Construção, no inglês, BIM (Building Information Model), vem aumentando e beneficiando a eficiência e o planejamento de projeto. Empresas que utilizam esta modelagem da informação devem reestruturar estratégias, implementar novos modelos, otimizar as várias etapas do processo. O desafio está na aplicação desses modelos em função dos entraves que ocorrem desde a estruturação dos processos, refletindo nas etapas posteriores de gestão, desenvolvimento e utilização da tecnologia. Este trabalho objetiva avaliar o impacto da implantação da modelagem no processo de gestão de pessoas em empresas projetistas. Para tanto, foi realizado um estudo de caso em uma empresa de arquitetura em fase de implementação do BIM, avaliando práticas de gestão e verificando se a implementação está levando em consideração as mudanças necessárias, convergindo em uma análise crítica e revisão bibliográfica.
\end{abstract}

\section{Introdução}

Diante do processo de recuperação da economia brasileira e o mercado imobiliário desacelerado, os fatores como o desemprego, a operação Lava Jato envolvendo grandes empresas do setor, as altas taxas de juros e a falta de crédito influenciaram negativamente toda a cadeia produtiva da construção civil.

Souza [1] relata que as pequenas empresas de projetos e escritórios de arquitetura são mais suscetíveis às instabilidades econômicas nos períodos de fraca demanda produtiva porque não estão preparadas e estruturadas para enfrentar crises no setor, pois falta gerenciamento e estratégias adequadas. Nesse cenário, o processo de gestão de pessoas nas empresas projetistas torna-se crítico e bastante relevante. A reestruturação dos seus modelos e processos visando o 
aproveitamento do seu potencial humano e revendo a forma de gerenciar seus talentos torna-se fundamental para a sobrevivência destas empresas em cenários de crise.

Corroborando, de acordo com Chiavenato [2], são as pessoas que processam todo o trabalho; portanto, são elas o ativo mais importante das organizações. A valorização do capital humano é uma tendência nas empresas, mostrando a importância na área de gestão de pessoas no que se refere aos aspectos relacionados aos colaboradores e sua função no ambiente laboral.

De acordo com Souza [1], as empresas da construção civil, do setor público e privado vêm confirmando que o uso da modelagem da informação da construção é uma tendência com forte impacto na gestão de pessoas e do processo de projetos. Os modelos digitais são compartilhados e integrados, favorecendo a gestão da informação e a compatibilização de projetos.

A implementação do BIM requer uma equipe bem treinada, com o conhecimento nas diversas disciplinas, colaboração e comunicação. São habilidades e competências que a gestão de pessoas nas empresas de projeto deve organizar, orientar e gerenciar, potencializando os resultados desejados. A modelagem da informação não depende somente de tecnologia e processos, mas fundamentalmente de pessoas.

Nesse sentido, o objetivo do trabalho é propor recomendações para os processos de gestão, com foco principal para o processo de gestão de pessoas para a empresa objeto do estudo de caso.

\section{Revisão de literatura}

\subsection{Gestão de Pessoas}

De acordo com Vilas, Ana, Bernardes e Rui [3], a gestão de pessoas é o processo de planejamento, organização, direção e controle de pessoal da empresa para promover o desempenho eficiente do pessoal, a fim de alcançar os objetivos organizacionais e os objetivos individuais, relacionados direta ou indiretamente com o trabalho.

Segundo Chiavenato [4], a gestão de pessoas se baseia em uma série de atividades integradas entre si, a fim de obter efeitos sinérgicos e multiplicadores tanto para as organizações quanto para as pessoas que nelas trabalham. Além de ser um conjunto integrado de processos dinâmicos e interativos, conta com seis processos básicos de acordo com a Figura 1.

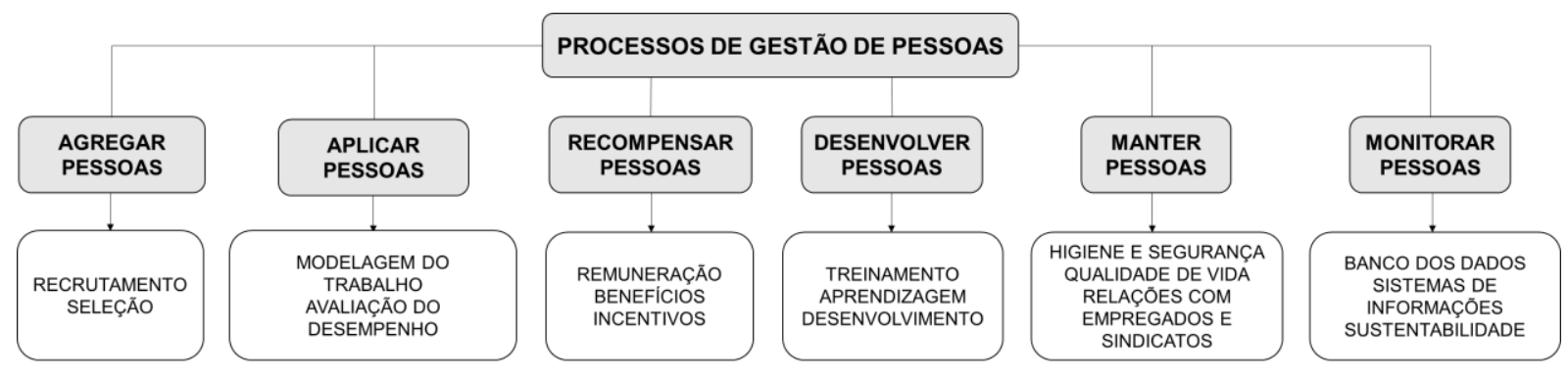

Figura 1: Processos de Gestão de Pessoas com base em Chiavenato [5].

Os processos de agregar, aplicar, recompensar, desenvolver, manter e monitorar pessoas são importantes ferramentas para a efetividade das ações e práticas da área de gestão de pessoas, conduzindo ao bom desempenho, ao aumento de produtividade, à competitividade e ao desenvolvimento de talentos nas organizações. 


\subsection{Modelagem da Informação da Construção}

Segundo Eastman [6], a modelagem da informação da construção é definida como conjunto de tecnologias e processos integrados com a criação, a utilização e a atualização de modelos digitais de uma construção, visando servir, de modo colaborativo, todos os participantes do empreendimento durante o seu ciclo de vida.

De acordo com Manzione [7], a modelagem da informação não é somente uma ferramenta de elaboração de projetos ou de gestão de obra, mas sim a integração de um sistema de informações obtidas de processos, de pessoas e de tecnologia, exigindo mudanças na organização do trabalho passando do modelo tradicional para o colaborativo, aberto e compartilhado.

\subsection{Gestão de pessoas na Modelagem da Informação da Construção}

Para Gil [8], as pessoas são de extrema importância para o sucesso de uma organização, pois são elas que gerenciam, comandam, executam, controlam atividades e processos em busca dos resultados com eficiência e eficácia, dos objetivos tanto organizacionais quanto individuais.

Quando o assunto é BIM, fala-se muito em softwares e tecnologias para o setor da construção civil. Porém, o foco na gestão de pessoas representa papel fundamental, sendo que a mudança de cultura inclui pessoas, processos e a forma como a organização se estrutura para desenvolver seus produtos e atingir os resultados desejados.

\section{Método de Pesquisa}

A pesquisa apresentada é do tipo qualitativa, conduzida através de um estudo de caso único. $\mathrm{O}$ presente artigo é produto de uma monografia produzida no contexto do Programa de Especialização em Gestão de Projetos da FDTE (Fundação para o Desenvolvimento Tecnológico da Engenharia), na Escola Politécnica da USP.

Segundo Yin [9], o estudo de caso baseia-se em uma estratégia de pesquisa em busca do entendimento de um fato atual em todo o seu contexto com abordagens específicas, coleta de dados e informações para que o pesquisador possa elaborar uma completa análise sobre os fatos ocorridos por meio das questões envolvidas, as quais serão estudadas.

Desse estudo, a revisão de literatura foi fundamental para análise e recomendações, apontando o tema Gestão de Pessoas e a Modelagem da Informação da Construção.

O método de pesquisa foi desenvolvido em três etapas conforme a Figura 2: 


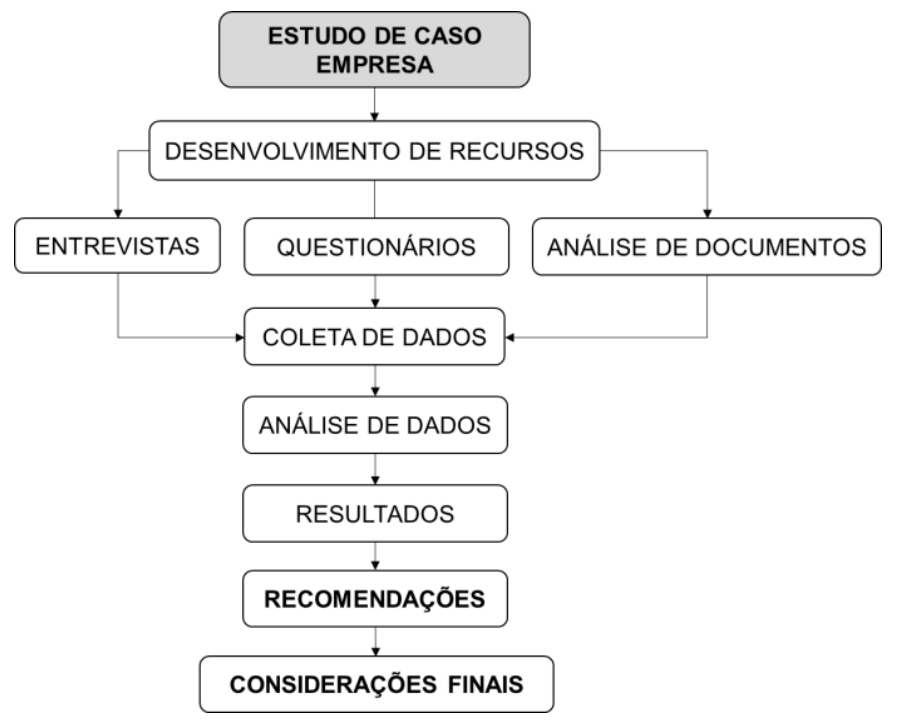

Figura 2: Método de pesquisa.

- Primeira etapa: empresa de arquitetura escolhida por se enquadrar nos objetivos do trabalho. Dados de coleta obtidos através de questionários e entrevistas com foco, na gestão de pessoas e a implementação do BIM, identificando os pontos fortes e os fracos da empresa;

- Segunda etapa: recomendações apresentadas para melhorias nas áreas abordadas nesta pesquisa;

- Terceira etapa: considerações finais em relação à implementação do conceito de modelagem da informação no processo de gestão de pessoas.

\section{Estudo de Caso}

O estudo de caso foi realizado em Curitiba, na empresa de arquitetura de pequeno porte com 35 anos de atuação no mercado de projetos com o objetivo de avaliar as práticas de gestão de pessoas e verificar se a implementação do BIM desde 2010 considerou as mudanças necessárias no processo de gestão de pessoas.

A escolha considerou o perfil e as características tais como área e tempo de atuação no segmento de escritórios de projeto, estrutura e número de funcionários, além da experiência obtida na fase de implementação da Modelagem da Informação da Construção.

Para analisar as práticas de gestão de pessoas durante o processo de implementação do BIM, foram realizadas entrevistas por meio de questionário aplicado aos sócios e aos funcionários da empresa.

A empresa possui 10 funcionários e os projetos executados em cinco áreas: arquitetura corporativa, imobiliária, residencial, sustentável, projetos complexos e de grande porte. É responsável pela elaboração do projeto em todas as suas fases de desenvolvimento, contemplando desde sua concepção, estudos de viabilidade, anteprojeto, estudo preliminar, projeto básico e projeto para execução e obra.

A estrutura organizacional baseia-se no modelo simples e funcional, com as áreas em Direção, Administrativa, Projetos e Design: 
- Direção: composta pelos dois sócios arquitetos diretores, responsáveis pela concepção formal, conceitual e validação dos projetos da empresa. Suas atribuições ainda se estendem ao planejamento estratégico, projetos arquitetônicos, processos de projetos, marketing, contratações, entre outros;

- Área Administrativa: cuida do processo burocrático de gestão de pessoas, marketing, controle orçamentário e jurídico;

- Área de projetos: possui arquitetos contratados como prestadores de serviço por projeto, além dos estagiários selecionados pelo convênio com universidades, no caso, Centro de Integraçao Empresa-Escola (CIEE);

- Área de design: conta com dois estagiários que modelam os projetos em 3D e auxiliam nas soluções de projeto dos empreendimentos. A empresa também contrata serviços de designers 3D e escritórios de maquete eletrônica para apresentar imagens foto-realistas dos seus projetos aos clientes.

O processo de implementação da tecnologia teve início a partir de diagnósticos obtidos sobre o posicionamento da empresa no mercado, suas práticas de gestão e dos processos de projeto, onde o objetivo era criar um diferencial em termos de qualidade e de satisfação dos clientes, fornecendo produtos com excelência e proporcionando um ambiente adequado, com todas as ferramentas necessárias ao aprimoramento do desempenho da equipe projetista.

Os aspectos considerados pelo diagnóstico foram a precisão e o workflow onde o fluxo de trabalho é uma sequência de atividades e tarefas que resultam em processos automatizados, com regras definidas, permitindo o acesso e a transmissão de dados para toda a equipe de projeto em tempo real, reduzindo as falhas, os atrasos e o desperdício.

No uso dos softwares, a empresa percebeu a necessidade de capacitação para a equipe através de treinamentos. $\mathrm{O}$ alinhamento à nova tecnologia foi fundamental para o desempenho da equipe envolvida no processo de projeto.

Segundo os sócios diretores da empresa, as estratégias para o processo de implementação do BIM foram determinadas através de acompanhamento, benchmarks para comparação de produtos e serviços e melhores práticas de gestão na arquitetura e na construção civil.

O processo de gestão de pessoas antes da implementação era colaborativo entre toda a equipe envolvida no processo de projeto, desde a concepção até a execução da obra. No entanto, não houve reestruturação nesses processos internos mesmo com a adoção do BIM.

As práticas de gestão de pessoas apresentam pontos negativos como a rotatividade dos profissionais sem vínculo empregatício com os arquitetos e a equipe contratada por projeto, a qual é desfeita no término do mesmo. Como também, não há plano de carreira, os salários se aproximam dos valores de mercado ou estão abaixo dele e não há benefícios ou ajuda de custo, como transporte, alimentação e outros.

Os gestores, a cada seis meses, realizam um feedback para avaliar o desempenho de cada profissional e estagiário envolvidos nos processos de projeto, verificando pontos positivos e aqueles que devem ser melhorados. Em contrapartida, os avaliados também apresentam suas sugestões para melhorar o sistema de trabalho.

Quanto ao ambiente, a empresa se preocupa em mantê-lo saudável e colaborativo, a fim de facilitar a comunicação interna entre toda a equipe. 
Os treinamentos são realizados com os próprios funcionários. Geralmente, a pessoa com maior conhecimento nos processos da empresa é quem aplica esse treinamento. Algumas palestras são ministradas na empresa com profissionais da área de arquitetura e engenharia.

As mudanças no processo de implementação do BIM foram específicas na utilização da nova tecnologia. O uso do CAD para o BIM, usando o software denominado Revit, trouxe redução do esforço de trabalho, aumento da produtividade e melhoria na qualidade dos projetos. Além disso, permitiu a produção e o gerenciamento de toda a informação de projeto através de um modelo 3D do edifício, com todas as disciplinas, de maneira simples e de fácil compartilhamento.

A empresa pretende manter o conhecimento gerado com o ciclo PDCA, uma ferramenta de gestão para a melhoria contínua dos processos através de ações como planejar (Plan), fazer (Do), checar (Check) e agir (Act). A equipe de trabalho procura solucionar os problemas durante a execução das tarefas analisando as causas, fazendo as correções para garantir os resultados esperados.

Com relação ao processo de seleção e contratação de pessoas, a mudança ocorreu na contratação de profissionais BIM, especialistas com conhecimentos e experiência associados à metodologia. A remuneração para os funcionários que utilizam o BIM foi alterada, resultando em aumento de salários.

Com a utilização do BIM, a empresa percebeu que a equipe laboral adquiriu mais conhecimentos no que diz respeito às obras e melhorou sua concentração na execução das tarefas e no uso da metodologia.

As pessoas estão motivadas, mas existem barreiras como a dificuldade de adaptação com a implementação do BIM, a falta de tempo e de planejamento para a aquisição do conhecimento, a resistência às mudanças pela equipe, a dificuldade para trabalhar em equipe simultaneamente, a parceria com outras empresas sem conhecimento do BIM, que fazem projetos complementares, gerando conflito ou incompatibilização entre as diversas disciplinas, arriscando perder prazos e gerar retrabalho.

Para os gestores, o impacto percebido no processo de gestão de pessoas corresponde ao maior rigor na escolha de profissionais e parceiros de trabalho. Contudo, no que diz respeito à tecnologia, a dificuldade na utilização da mesma foi bem maior.

\subsection{Análises}

Com as informações obtidas do questionário e os dados fornecidos pelos sócios diretores, tornase necessário a realização de uma análise crítica referente às práticas utilizadas no processo de gestão de pessoas na fase de implementação do BIM destacando os pontos positivos e negativos, conforme a tabela 1 . 
Tabela 1: Pontos positivos e negativos referentes à gestão de pessoas na implementação do BIM

\section{Pontos Negativos}

- Falta de alinhamento entre a gestão de pessoas, a estrutura organizacional e o planejamento estratégico;

- Prática de gestão de pessoas frágil e ineficiente;

- Falta de conhecimento para o uso da tecnologia (softwares) pela equipe, necessitando capacitação e treinamento;

- Escassez de recursos financeiros e alto custo para realizar as mudanças na estrutura, tanto de equipamentos de tecnologia como de profissionais capacitados;

- Não ocorreu a reestruturação nos processos de gestão de pessoas;

- Não há vínculo empregatício;

- Não há plano de carreira, os salários se aproximam dos valores de mercado, ou estão abaixo dele, como também não há benefícios ou ajuda de custo (transporte, alimentação e outros);

- Barreiras como a dificuldade de adaptação ao uso do BIM, a falta de planejamento na aquisição do conhecimento, a resistência às mudanças, trabalho em equipe simultaneamente, parceria com empresas sem conhecimento em BIM e incompatibilização entre as diversas disciplinas.

\section{Pontos Positivos}

- Proporciona um ambiente adequado, saudável e colaborativo com as ferramentas necessárias para aprimorar o desempenho e a comunicação interna entre toda a equipe;

- Utilização de precisão e workflow para diminuir as falhas no processo, a confiabilidade nos procedimentos, além de evitar atrasos e desperdícios;

- Estratégias para o processo de implementação do BIM foram determinadas através de benchmarks de melhores práticas de gestão na arquitetura e na construção civil;

- Cada seis meses, os gestores realizam feedback para avaliar o desempenho de cada funcionário e estagiário;

- Funcionários apresentam suas sugestões para melhorar o sistema de trabalho;

- Palestras na empresa com profissionais externos na área de arquitetura e engenharia;

- Treinamento para a equipe de projeto com a contratação de um especialista em BIM;

- Uso do CAD para o BIM, usando o Revit, trouxe redução do esforço de trabalho, aumento da produtividade e melhoria na qualidade dos projetos, permitindo a produção e o gerenciamento de toda a informação de projeto através de um modelo 3D do edifício;

- Remuneração para os funcionários que utilizam o BIM resultou em aumento de salários;

- Com o BIM, a equipe adquiriu mais conhecimentos no que diz respeito às obras e melhorou a execução das tarefas e no uso da metodologia;

- Utiliza o ciclo PDCA.

\subsection{Recomendações}

A análise do estudo de caso demonstrou que a prática da gestão realizada demanda uma série de adequações que passam pela reestruturação dos processos. No entanto, as recomendações 
têm como foco principal a gestão de pessoas e a implementação do BIM com o objetivo de revisar e possibilitar a proposição de melhorias no processo gerencial da empresa. Conforme a Tabela 2, são apresentados os problemas com suas recomendações.

Tabela 2: Problemas apresentados e suas recomendações

\begin{tabular}{|c|c|c|}
\hline & Problemas apresentados & Recomendações \\
\hline 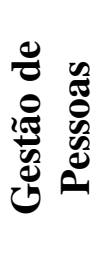 & $\begin{array}{l}\text { Prática de gestão de pessoas frágil e } \\
\text { ineficiente; } \\
\text { Não há vínculo empregatício e plano } \\
\text { de carreira e salários; } \\
\text { Rotatividade de profissionais é alta. }\end{array}$ & $\begin{array}{l}\text { Mudança de atitude dos sócios com seus } \\
\text { profissionais reconhecendo a equipe como } \\
\text { parte integrante da empresa. }\end{array}$ \\
\hline 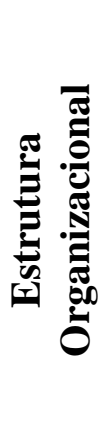 & $\begin{array}{l}\text { Estrutura organizacional simples e } \\
\text { funcional, concentrada na figura dos } \\
\text { sócios envolvidos em todos os } \\
\text { processos de gestão da empresa, o } \\
\text { que acarreta uma sobrecarga de } \\
\text { trabalho. }\end{array}$ & $\begin{array}{l}\text { Alinhar a estrutura organizacional com o } \\
\text { planejamento estratégico para que as } \\
\text { atividades sejam executadas de acordo com } \\
\text { os projetos; } \\
\text { Gestão de pessoas deve adequar a quantidade } \\
\text { de pessoas e as capacidades técnicas para o } \\
\text { desempenho das tarefas; } \\
\text { Matriz de responsabilidade RACI deve ser } \\
\text { utilizada. }\end{array}$ \\
\hline
\end{tabular}

Sócios diretores elaboram o planejamento estratégico com metas e objetivos definidos, sem alinhamento com os demais processos de gestão da empresa.
Estabelecer o alinhamento dos processos de gestão com o planejamento estratégico para acompanhar o seu desempenho e posicionamento no mercado.

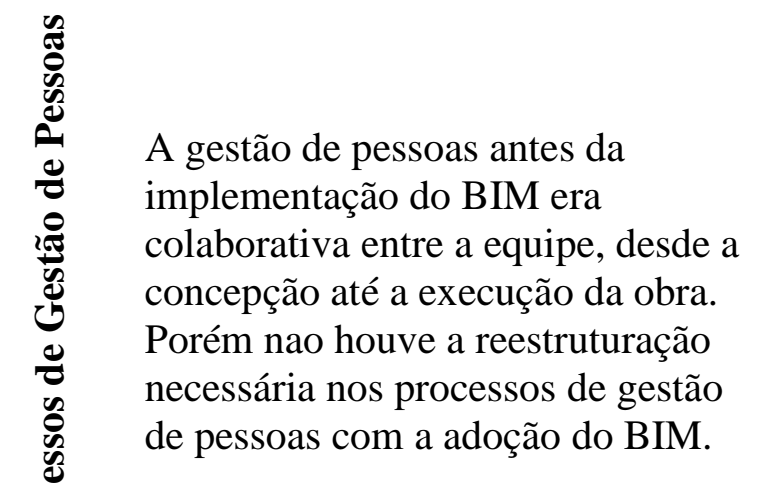

Adotar os seis processos de gestão de pessoas (agregar, aplicar, recompensar, desenvolver, manter e monitorar), assumindo uma postura estratégica para lidar com a equipe; Capacitar e desenvolver a equipe com conhecimentos e habilidades, recompensar desempenhos e comportamentos eficazes, estimular o comprometimento das pessoas, além de criar um ambiente de trabalho produtivo, beneficiando seus funcionários, promovendo satisfação pessoal e sucesso corporativo. 
Processo de recrutamento e seleção de pessoas é informal e de responsabilidade dos sócios diretores;

Contratação feita de acordo com as necessidades e o número de projetos e serviços agregados ao processo de projeto;

Não há política de remuneração definida, seguindo valores de mercado, como também, falta de planos de carreira para os funcionários da empresa.
Formalizar e alinhar o processo de recrutamento e seleção com o planejamento estratégico;

Fazer a descrição de cargos e funções; Aplicar a avaliação de desempenho para mensurar o potencial de seus funcionários; Verificar a necessidade de treinamentos e competências;

Definir política de remuneração para o equilíbrio interno da estrutura de cargos e salários;

Criar planos de carreira para os profissionais, buscando maior comprometimento com os objetivos da empresa.

\section{: $\quad$ Maior impacto e preocupação estava no uso da tecnologia (softwares), e não com as pessoas que operariam o BIM; \\ Nao houve reestruturação necessária para alinhar e adequar os processos gerenciais com o BIM; \\ A empresa passou por um período de crise financeira com a baixa demanda por projetos levando ao corte de investimentos, no que se refere à tecnologia e pessoal.}

Com a retomada da estabilidade financeira e o aumento da demanda de projetos, a empresa tem como prioridade retomar e dar continuidade à implementação do BIM, fazendo um levantamento de custos para a atualização de softwares e equipamentos, e a necessidade de profissionais capacitados para a operacionalização dos processos da equipe envolvida nos projetos.
Não há modelo de gestão de pessoas. Os sócios diretores são responsáveis por todas as decisões de contratação, recrutamento e seleção.
Implantar o modelo de gestão por competências (mapeamento, mensuração, remuneração, seleção, desenvolvimento, avaliação de desempenho e plano de desenvolvimento por competências); O conjunto de Conhecimentos, Habilidades e Atitudes (CHA) deve ser utilizado na execução de tarefas, associados aos objetivos e metas da empresa.

Para a implantação do modelo de gestão de pessoas por competências foram relacionados aspectos básicos de mudanças e ações que podem servir como recomendações para a empresa no estudo de caso, conforme a Tabela 3: 
Tabela 3: Ações propostas para a gestão de pessoas por competência

\section{Diagnóstico}

- Levantar a situação atual da gestão de pessoas através de feedbacks e relatórios sobre os processos utilizados;

- Implementar a avaliação de desempenho para analisar os conhecimentos, habilidades e atitudes dos funcionários;

- Realizar o mapeamento de competências;

- Definir as competências em BIM;

- Verificar os gaps entre as necessidades da empresa, as exigências de cada cargo e as competências de cada colaborador.

\section{Implementação de Processos}

- As mudanças devem ser aplicadas de forma gradual no ajuste das estruturas de gestão de pessoas. A partir do diagnóstico, as ações a serem implementadas são:

- Cargos com suas competências definidas em conformidade com o mapeamento das necessidades da empresa;

- Formas de remuneração estabelecidas e alinhadas com as novas exigências dos cargos e suas competências determinadas;

- Contratações devem ter suporte no recrutamento por competências, com a aplicação de técnicas de seleção para avaliar o candidato;

- Avaliações de desempenho devem ser realizadas periodicamente, enfatizando a identificação das competências e seu respectivo desenvolvimento.

\section{Treinamento dos Funcionários}

- Análise das lacunas (gaps) existentes para definição da necessidade de treinamento com foco nas competências essenciais e específicas.

\section{Recrutamento}

- Buscar novos profissionais quando os recursos disponíveis são deficientes;

- Recrutamento interno, com recursos de pessoal dentro da empresa, através de promoções ou deslocamento de um profissional para a vaga;

- Recrutamento externo, quando a competência exigida requer habilidades para trabalhos complementares e que não são comuns à empresa.

\section{Mensuração dos Resultados}

- Criação de um modelo para acompanhamento dos resultados através de feedbacks, avaliações e mapeamentos periódicos;

- Os gestores podem identificar a distância dos funcionários em relação às necessidades da empresa;

- Alinhar a programação de treinamentos, recrutamento e demais avaliações. 


\section{Conclusões}

Pelo que foi exposto, a recomendação para melhorias prende-se à necessidade de uma reestruturação nos processos das práticas de gestão, principalmente no que se refere à gestão de pessoas, tendo como modelo proposto a gestão por competências.

O posicionamento dos sócios em relação às mudanças necessárias nos processos de gestão é o fator mais importante para a implementação de um modelo de gestão de pessoas, motivando os seus colaboradores e buscando os resultados esperados pela empresa.

$\mathrm{Na}$ implementação de modelagem da construção, a gestão de pessoas é estratégica e objetiva tornar a relação entre pessoas, processos e tecnologias mais colaborativa e produtiva, através de seus conhecimentos, habilidades e competências.

A demanda pela tecnologia da modelagem da informação da construção levantou a questão sobre a escassez de pessoas com habilidades e competências BIM, onde a educação adequada é fundamental para que as equipes de projeto possam adquirir conhecimentos e desenvolver as competências necessárias.

Verifica-se no Brasil, tanto no setor público como privado, movimentos que confirmam o uso da modelagem da informação da construção como uma tendência. Por outro lado, os processos de gestão de pessoas, principalmente no que se refere à definição de competências, não vêm sendo adaptados de modo possibilitar que as pessoas e suas competências estejam aptas a operacionalizar os processos e aplicar as tecnologias carregadas pelo conceito BIM.

Grande parte das empresas projetistas ainda não percebeu a importância da gestão de pessoas e como ela pode contribuir para a melhoria da performance da organização. Dessa forma, este artigo pode colaborar na compreensão e na implantação dos métodos e processos de gestão das empresas, sistematizando-os com foco na otimização e na qualificação, promovendo uma reflexão entre as empresas e os profissionais que atuam no mercado da construção civil.

\section{Referências}

[1] F. R. Souza, "Implementação de modelo de gestão para pequenas empresas de projeto de edifícios", Dissertação (Mestrado), Escola Politécnica da Universidade de São Paulo, São Paulo, Brasil, 2009.

[2] I. Chiavenato. "Recursos Humanos", 09a Edição, São Paulo, Elsevier, 2009.

[3] B. Vilas, A. Ana, A. Bernardes, O. Rui, "Gestão estratégica de pessoas", 01 a Edição, São Paulo, Elsevier, 2009.

[4] I. Chiavenato. "Gestão de pessoas: o novo papel dos recursos humanos nas organizações", Barueri, Manole, 2014.

[5] I. Chiavenato. "Gestão de pessoal: o novo papel dos recursos humanos nas organizações",

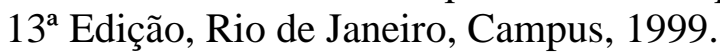

[6] C. Eastman. "BIM handbook: a guide to building information modeling for owners, managers, designers, engineers, and contractors." USA. John Wiley \& Sons, Inc., 2011.

[7] L. Manzione. "Desafios para a implementação do processo de projeto colaborativo: análise do fatos humano", Salvador, Bahia, Escola Politécnica da USP, 2011.

[8] A. C. Gil. "Métodos e técnicas de pesquisa social", São Paulo, Atlas, 2008.

[9] R. K. Yin. "Estudo de caso: planejamento e métodos", 2a Edição, Porto Alegre, SãoPaulo, Bookman, 2001. 